\title{
Hybrid thermosets from vinyl ester resin and acrylated epoxidized soybean oil (AESO)
}

\author{
S. Grishchuk ${ }^{1}$, J. Karger-Kocsis ${ }^{2,3 *}$ \\ ${ }^{1}$ Institut für Verbundwerkstoffe GmbH (Institute for Composite Materials), Kaiserslautern University of Technology, \\ POBox 3049, D-67653 Kaiserslautern, Germany \\ ${ }^{2}$ Department of Polymer Engineering, Faculty of Mechanical Engineering, Budapest University of Technology and \\ Economics, H-1111 Budapest, Hungary \\ ${ }^{3}$ Department of Polymer Technology, Faculty of Mechanical Engineering and Built Environment, Tshwane University of \\ Technology, Pretoria, 0001, South Africa
}

Received 24 June 2010; accepted in revised form 1 September 2010

\begin{abstract}
A series of hybrids composed of styrene crosslinkable vinyl ester (VE) and acrylated epoxidized soybean oil (AESO) were produced via free radical-induced crosslinking. The VE/AESO ratio was changed between 75/25 and 25/75 wt $\%$. Moreover, to support phase grafting the VE/AESO $=50 / 50 \mathrm{wt} \%$ hybrid was modified with phthalic anhydride in various amounts $(1,5$ and $10 \mathrm{wt} \%)$. The structure of the hybrid systems was investigated by dynamic mechanical thermal analysis (DMTA), differential scanning calorimetry (DSC), and atomic force microscopy (AFM). The properties of the systems were assessed by static flexural and fracture mechanical tests. The resistance to thermal degradation was inspected by thermogravimetric analysis (TGA). The results suggested that the hybrids have an interpenetrating network (IPN) structure. With increasing AESO content the stiffness (modulus), strength and glass transition temperature $\left(T_{\mathrm{g}}\right)$ of the hybrids decreased, whereas their ductility increased. Phthalic anhydride caused an adverse trend. Both the fracture toughness and fracture energy increased with increasing AESO content. They were less affected by adding phthalic anhydride phase couplant. Interestingly, the hybrids outperformed the parent VE and AESO in respect to resistance to thermal degradation.
\end{abstract}

Keywords: thermosetting resin, acrylated epoxidized soybean oil (AESO), fracture toughness, vinyl ester, interpenetrating network (IPN)

\section{Introduction}

The synthesis of polymers from renewable resources is a preferred research topic nowadays. This is due to the eco-friendly classification of the related polymers which contribute to environment sustainability and to diminution of global warming by replacement of petroleum-based resins.

Plant oils, being unsaturated triglycerides, are very promising raw materials for the 'greening' of thermosets. This note especially holds for soybean oil which may be 'genetically engineered' for such polymer-related application. However, the double bonds along the fatty acid chain in the triglycerides, even if the unsaturation level in the compounds is high enough, are less reactive towards free radicalinduced crosslinking than those in terminal positions. This is the reason why a large body of works addressed the 'functionalization' of plant (vegetable) oils to support the free radical-caused crosslinking and co-crosslinking (with other comonomers) reactions (e.g. $[1,2])$. The related synthetic route starts usually with the epoxidation of the double bonds. Afterwards, these epoxy groups react with the carboxyl groups of selected acrylic acids. The resulting 
epoxidized and acrylated epoxidized vegetable oils can be cured alone and also used in epoxy formulations (e.g. [3-5]) and unsaturated polyester resins, as well (e.g. [6, 7]). It is worth noting that different strategies exist for both the functionalization and the co-curing of plant oils (e.g. [1, 2]). The role of the functionalized plant oils in the corresponding recipes may be different: reduction of styrene content and thus its emission (e.g. [6]), toughening agent (e.g. [8, 9]), plasticizer, etc. The use of oils from renewable resources offers also other benefits, such as low toxicity and inherent biodegradability. Beside of the use of functionalized plant oils as additives, several attempts were made to fully replace petroleum-based resins, especially unsaturated polyesters and epoxies in the related composites (e.g. [1, 2, 10-12]). Interestingly, less attention was paid to hybrid thermosets with interpenetrating network (IPN) structure. Under hybrid systems those composed of petroleum-based resins and functionalized plant oils are meant in this paper. By contrast, IPN-structured plant oils have been in focus of investigations since end of 1970s (e.g. [13]). It is noteworthy that IPN-structured thermosets can be produced also in one-pot synthesis. Major advantage of the resulting simultaneous IPNs is that their properties, including the glass transition temperature $\left(T_{\mathrm{g}}\right)$ can be set in-between those of the parent resins.

However, it is difficult to fully replace petroleumbased polymeric materials by those from renewable resources. The problems with biobased polymers are mainly due to their inferior mechanical and thermo-physical properties in comparison with conventional petroleum-based polymers that are intended to be replaced. Considering the fact that functionalized plant oils, when cured alone or even with styrene as reactive comonomer, yield rubberlike materials $[1,2,14,15]$, they have to be combined with such petroleum-based resins which show high stiffness, strength and $T_{\mathrm{g}}$ owing to their chemical build-up and tightly crosslinked structure. For that purpose vinyl ester resin (VE) is especially well suited as it contains stiff aromatic units. Accordingly, the aim of this study was to determine the structure-related mechanical and thermal performances of VE/acrylated epoxidized soybean oil (AESO) hybrids with possible IPN structure. To support the formation of the latter the VE/AESO ratio was varied between 25/75 and 75/25 wt \%. A further aim was to check whether the creation of a more grafted IPN structure is accompanied with additional property improvements. Grafted IPN means that the intermingled phases (i.e. IPN) are chemically linked to each other via suitable chemical reactions [16]. For additional grafting phthalic anhydride has been selected that may react with both VE (hydroxyl groups) and AESO (epoxy and hydroxyl groups), and its effect was investigated in the system VE/AESO = 50/50 wt $\%$. Phthalic anhydride already proved to be a promising curing agent for epoxidized plant oils (e.g. [17]). Further, its aromatic structure should promote the 'stiffening' of the phase structure of the hybrids on molecular level.

\section{Experimental \\ 2.1. Materials}

The styrene diluted ( $\sim 30 \mathrm{wt} \%$ ) bisphenol-A type vinyl ester (VE; Daron-XP-45-A2 from DSM Composite Resins, Zwolle, The Netherlands) had the following characteristics: Hydroxyl value $\sim 158 \mathrm{mg}(\mathrm{KOH}) / \mathrm{g}$, acid value $<4 \mathrm{mg}(\mathrm{KOH}) / \mathrm{g}$, viscosity $175-225 \mathrm{mPa} \cdot \mathrm{s}$ at $23^{\circ} \mathrm{C}$, and density $1.08 \mathrm{~g} / \mathrm{ml}$ at $23^{\circ} \mathrm{C}$. Acrylated epoxidized soybean oil (AESO), containing ca. 3500 ppm (by liquid chromatography) monomethyl ether hydroquinone as inhibitor, was purchased from Sigma-Aldrich Chemie GmbH (Taufkirchen, Germany). The characteristics of AESO are: viscosity $29.1 \mathrm{~Pa} \cdot \mathrm{s}$ at $25^{\circ} \mathrm{C}$, acid value $8.08 \mathrm{mg}(\mathrm{KOH}) / \mathrm{g}$, epoxy value $=$ $8.50 \mathrm{mg}(\mathrm{KOH}) / \mathrm{g}$, density $1.04 \mathrm{~g} / \mathrm{ml}$ at $25^{\circ} \mathrm{C}$. Phthalic anhydride (melting point $=129-133^{\circ} \mathrm{C}$; grade: purum, containing $\sim 2 \%$ phthalic acid) was also purchased from Sigma-Aldrich Chemie $\mathrm{GmbH}$. Anti-foaming agent BYK-A 555 was received from BYK Chemie GmbH (Wesel, Germany). Dibenzoyl peroxide (BPO; Perkadox CH50L - peroxide content $50 \mathrm{wt} \%$ ) and $\mathrm{N}, \mathrm{N}$-diethyl aniline (DEA) accelerator were purchased from Akzo Nobel (Düren, Germany).

The following VE/AESO combinations were made: $75 / 25,50 / 50$ and $25 / 75 \mathrm{wt} \%$. For reference purpose VE and AESO were produced separately. Curing of the resins occurred by adding BPO and DEA in 1.5 and $0.15 \mathrm{wt} \%$, respectively. 1,5 and $10 \mathrm{wt} \%$ of phthalic anhydride (A) was used for additional crosslinking for the VE/AESO $=50 / 50 \mathrm{wt} \%$ sys- 
tem. To avoid foaming all formulations contained $0.4 \mathrm{wt} \%$ BYK-A 555.

\subsection{Specimens preparation}

The resins were prepared as given below. VE and AESO were mixed together at room temperature (RT) for 4 min with a cogged-wheel mixer at 800 revolutions per minute $[\mathrm{rpm}]$. Then, in the same procedure $1.5 \mathrm{wt} \%$ of $\mathrm{BPO}$ was dissolved and the obtained mixtures were degassed in vacuo. Afterwards $0.15 \mathrm{wt} \%$ of accelerator was introduced. The resin formulations were mixed for additional $3 \mathrm{~min}$ by $800 \mathrm{rpm}$, degassed again and poured in open moulds fabricated from polytetrafluoro ethylene. Plates $\left(100 \times 10 \times 4 \mathrm{~mm}^{3}\right.$, length $\times$ width $\times$ thickness) and compact tension (CT) specimens $(35 \times$ $35 \times 4 \mathrm{~mm}^{3}$, length $\times$ width $\times$ thickness) were produced in the cavities of the moulds. For crosslinking of the resin systems the following regime was set: RT for 1 hour [h], $50^{\circ} \mathrm{C}$ for $15 \mathrm{~min}, 80^{\circ} \mathrm{C}$ for $30 \mathrm{~min}, 140^{\circ} \mathrm{C}$ for $30 \mathrm{~min}$, and finally $180^{\circ} \mathrm{C}$ for $1 \mathrm{~h}$. The moulds were then cooled to ambient temperature over night and the specimens removed.

\subsection{Materials characterization}

The phase structure of the cured samples was studied by dynamic-mechanical thermal analysis (DMTA) and differential scanning calorimetry (DSC), respectively. DMTA traces (storage modulus, $E^{\prime}$; and the mechanical loss factor, $\tan \delta v s$. temperature) were determined by a DMA Q800 device of TA Instruments (New Castle, DE, USA) on rectangular specimens $\left(60 \times 10 \times 3 \mathrm{~mm}^{3}\right.$; length $\times$ width $\times$ thickness) in 3-point bending configuration (span length: $50 \mathrm{~mm}$ ) at $1 \mathrm{~Hz}$ with an oscillation amplitude of $50 \mu \mathrm{m}$. The scan rate in the selected temperature range $\left(T=-100 \ldots+250^{\circ} \mathrm{C}\right)$ was $1{ }^{\circ} \mathrm{C} / \mathrm{min}$.

DSC traces were recorded by a DSC 821 device of Mettler Toledo (Gießen, Germany) at $10^{\circ} \mathrm{C} / \mathrm{min}$ heating rate in the temperature range of -100 to $+250^{\circ} \mathrm{C}$. The aluminum pans used were filled with ca. $10 \mathrm{mg}$ resin sample. For the $T_{\mathrm{g}}$ determination of the resins the mid point of the glass transition step was considered.

Further information on the morphology was from atomic force microscopic (AFM) studies. They were carried out on polished samples of the VE/AESO = $50 / 50 \mathrm{wt} \%$ system. The surface profile was scanned by AFM (Veeco/Digital Instruments $\mathrm{GmbH}$,
Mannheim, Germany) in tapping mode, and the related height- and phase-contrast images captured. Commercial silicon cantilever (Pointprobe ${ }^{\circledR} \mathrm{NCH}$ ) with a nominal tip radius of less than $10 \mathrm{~nm}$ (120 $\mu \mathrm{m}$ cantilever length, $4 \mu \mathrm{m}$ thickness, $30 \mu \mathrm{m}$ width and spring constant at $42 \mathrm{Nm}^{-1}$ (Nanosensors, Neuchatel, Switzerland)) was employed under its fundamental resonance frequency of about $330 \mathrm{kHz}$. The scan rates were set at $0.5 \mathrm{~Hz}$ for all images.

The flexural properties, namely, modulus, strength and strain of the hybrid resins, were determined on rectangular specimens $\left(60 \times 10 \times 3 \times \mathrm{mm}^{3}\right.$; length $\times$ width $\times$ thickness; 5 specimens for each composition) in three point bending at RT on a Zwick 1474 machine (Zwick GmbH, Ulm, Germany) according to EN63. The span length of the specimens was $50 \mathrm{~mm}$ and their loading occurred with deformation rate of $v=1 \mathrm{~mm} / \mathrm{min}$.

Fracture energy $\left(G_{\mathrm{c}}\right)$ and fracture toughness $\left(K_{\mathrm{c}}\right)$ were determined on CT specimens (min. 5 specimens for each composition) according to ISO 13586-1 standard. The CT specimens were initially notched by sawing. Their notch root was sharpened by a fresh razor blade prior to their tensile loading (mode I) at room temperature on a Zwick 1445 machine (Zwick GmbH, Ulm, Germany) with a crosshead speed of $v=1 \mathrm{~mm} / \mathrm{min}$. Surfaces of the broken CT specimens were inspected in a scanning electron microscope (SEM, JSM-5400 of Jeol, Tokyo, Japan). To avoid electric charging the fracture surface was sputter coated with an $\mathrm{Au} / \mathrm{Pd}$ alloy. The resins were subjected to thermogravimetric analysis (TGA) in a DTG-60 device of Shimadzu Deutschland GmbH (Duisburg, Germany). The TGA experiments were conducted under nitrogen atmosphere in the temperature range $T=+25^{\circ} \mathrm{C} \ldots$ $+600^{\circ} \mathrm{C}$ with heating rate $20^{\circ} \mathrm{C} / \mathrm{min}$.

\section{Results and discussion}

\subsection{Phase structure}

Figure 1 depicts the storage modulus $\left(E^{\prime}\right)$ and mechanical loss factor $(\tan \delta)$ as a function of temperature $(T)$ for the VE and for the VE/AESO hybrids. The glass transition temperatures $\left(T_{\mathrm{g}}\right)$ and maximal values of $\tan \delta$ are presented in Table 1 for the systems studied. Unfortunately, the DMTA curve of reference AESO could not be captured in three-point bending mode due to premature failure. 


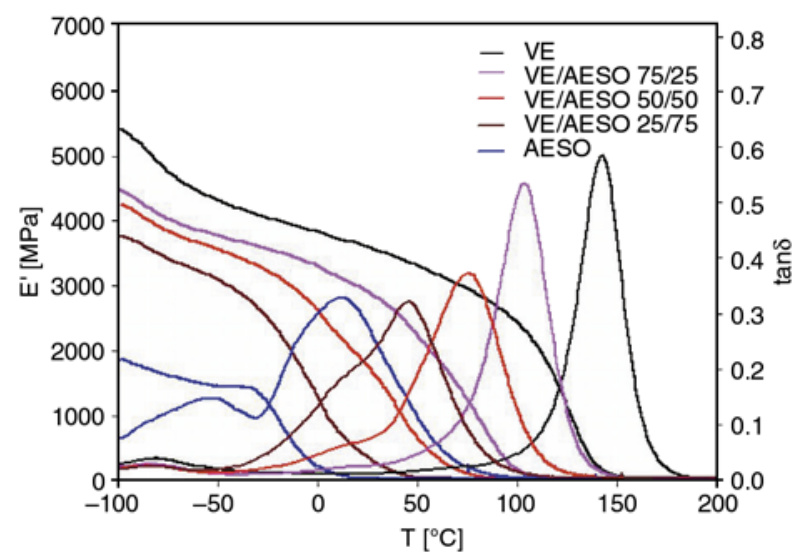

Figure 1. $E^{\prime}$ and tand as a function of $T$ for crosslinked VE, AESO and VE/AESO hybrids of different compositions

Therefore the crosslinked AESO was characterized by DMTA in tension mode. Two broad $T_{\mathrm{g}}$ relaxations, viz. at $T \sim-50^{\circ} \mathrm{C}$ and $T \approx 15^{\circ} \mathrm{C}$, respectively, were detected for the polymerized AESO. It is due to the multi-functionality and high unsaturation level of the AESO: network sections of different crosslink densities (including hyperbranched structures as demonstrated later) are formed owing to homo- and copolymerization reactions of the double bonds of different acrylated triglycerides, present in the soybean oil. Additionally, homopolymerization of the residual epoxy groups of AESO and their reaction with the secondary hydroxyl groups of AESO at elevated temperatures might have also influenced the crosslinking. The parent VE shows two relaxations: the $\alpha$-peak or $T_{\mathrm{g}}$ is at $T \approx 140^{\circ} \mathrm{C}$, while the $\beta$-one is at $T \approx-80^{\circ} \mathrm{C}$. All VE/ AESO hybrids display the $\beta$-relaxation in the same temperature region as VE. However, the change in the shape of the $\alpha$-peaks of the VE/AESO hybrids suggests that the morphology becomes more complex with the AESO content (see also the onset of a shoulder at the lower temperature flank of the $T_{\mathrm{g}}$ peak). It is clearly seen that with increasing AESO content the stiffness $\left(E^{\prime}\right)$ in the glassy state is monotonously decreasing. This is accompanied by a similar change in the $T_{\mathrm{g}}$ (read as the peak temperature of the $\alpha$-transition in this case). Moreover, the $T_{\mathrm{g}}$ peak becomes less intensive and more broad with increasing AESO content of the hybrids. On the other hand, no peak doubling can be observed indicating the good compatibility between AESO and VE. The appearance of a shoulder ( $\alpha^{\prime}$-relaxation) in the $\tan \delta v s . T$ trace of the hybrids with $50 \mathrm{wt} \%$ AESO and more, can be attributed AESOrelated homo- and copolymerization reactions. This is supported by the fact that the position of the shoulder agrees well with that of the $\alpha$-relaxation of the polymerized AESO - cf. Figure 1. The slight shift towards higher temperatures in the position of the shoulder of the AESO-rich VE/AESO hybrids compared to the crosslinked AESO hints for grafting, which manifests itself in the reduced segmental mobility. Moreover, peak broadening is a usual feature in graft-IPN structured thermosets. On the other hand, the great amount of possible relaxations modes acting in triglyceride-based polymers results per se in a broad $T_{\mathrm{g}}$ peak [14]. Based on the above results one can conclude that AESO works as a reactive plasticizer in VE. Note that a reduction in $T_{\mathrm{g}}$ is usually due to less tight crosslinking (co-network) which covers also the formation of IPN. According to the opinion of the authors the intensity reduction of the $T_{\mathrm{g}}$ peak can be ascribed to some constraint effects on supramolecular level which supports the presence of IPN. It is noteworthy that two $T_{\mathrm{g}}$ steps were resolved in DSC (cf. Table 1 and Figure 3a) the possible reason of which was disclosed above.

Table 1. Glass transition temperatures $\left(T_{\mathrm{g}}\right)$ of the VE and VE/EASO hybrids Designation: (P)AESO - crosslinked AESO

\begin{tabular}{|c|c|c|c|c|c|}
\hline \multirow{3}{*}{ Material } & \multicolumn{5}{|c|}{ Properties } \\
\hline & \multirow{2}{*}{$\begin{array}{c}\text { DSC } \\
T_{\mathrm{g}}\left[{ }^{\circ} \mathbf{C}\right]\end{array}$} & \multicolumn{4}{|c|}{ DMA } \\
\hline & & $\mathbf{T}_{\mathrm{g}}(\alpha)\left[{ }^{\circ} \mathrm{C}\right]$ & $T_{g}\left(\alpha^{\prime}\right)\left[{ }^{\circ} \mathbf{C}\right]$ & $\max \tan \delta$ at $T_{g}(\alpha)$ & $\max \tan \delta$ at $T_{g}\left(\alpha^{\prime}\right)$ \\
\hline $\mathrm{VE}$ & 114 & 143 & - & 0.59 & - \\
\hline VE/AESO 75/25 & 93 & 105 & $\sim 20$ & 0.53 & 0.03 \\
\hline VE/AESO 50/50 & 45 & 78 & $\sim 15$ & 0.37 & 0.07 \\
\hline VE/AESO 50/50 A1\% & 46 & 78 & $\sim 15$ & 0.38 & 0.06 \\
\hline VE/AESO 50/50 A5\% & 47 & 79 & $\sim 15$ & 0.39 & 0.05 \\
\hline VE/AESO 50/50 A10\% & 48 & 79 & $\sim 15$ & 0.41 & 0.05 \\
\hline VE/AESO 25/75 & 26 & 48 & $\sim 15$ & 0.32 & 0.19 \\
\hline (P)AESO & $-26(-4)$ & 14 & -52 & 0.33 & 0.15 \\
\hline
\end{tabular}

Note: $\alpha^{\prime}$ corresponds to the shoulder on $\tan \delta v s . T$ trace 


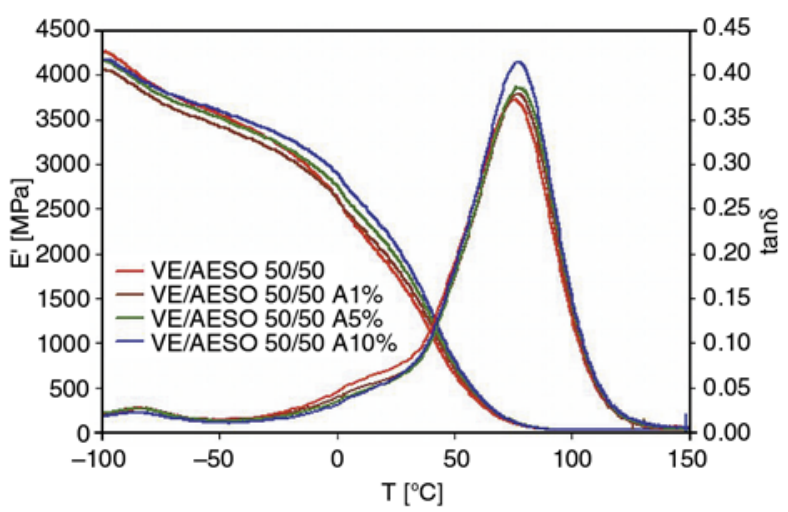

Figure 2. $E^{\prime}$ and $\tan \delta$ as a function of $T$ for $\mathrm{VE} / \mathrm{AESO}=$ $50 / 50 \mathrm{wt} \%$ hybrid with and without phthalic anhydride (A) in different amounts

Additional incorporation of phthalic anhydride (A) improved the glassy storage modulus of the corresponding hybrid via the supposed grafting (cf. Figure 2). With increasing A content the $E^{\prime}$ values were monotonously, but only marginally enhanced above RT. Similarly, no change could be resolved in the $\tan \delta v s . T$ traces as a function of added A. This finding is in contrast to the expectation and requires further investigations.

The DSC results are in harmony with the DMTA ones: the $T_{\mathrm{g}}$ step is shifted to lower temperatures with increasing AESO content of the hybrids (cf. Figure 3a), and modification with A did not change much the position of $T_{\mathrm{g}}$ of the $\mathrm{VE} / \mathrm{AESO}=$ $50 / 50 \mathrm{wt} \%$ (cf. Figure $3 \mathrm{~b}$ ). The difference in the $T_{\mathrm{g}}$ values based on DSC and DMTA can be explained by the different measuring principles and heating rates selected. The fact that the crosslinked AESO shows two $T_{\mathrm{g}}$ steps already suggests how complex its structure is. This is linked with the peroxyinduced various crosslinking reactions in AESO.

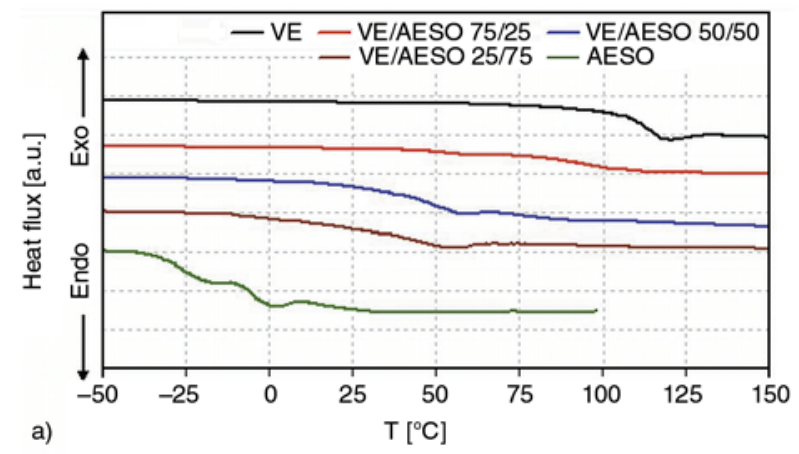

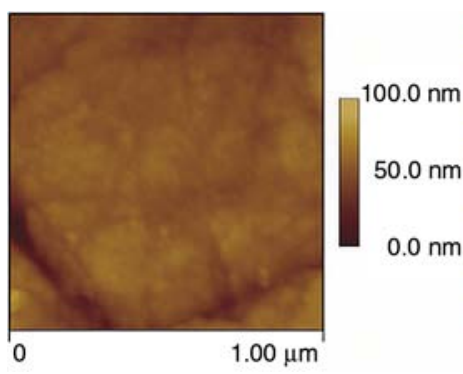

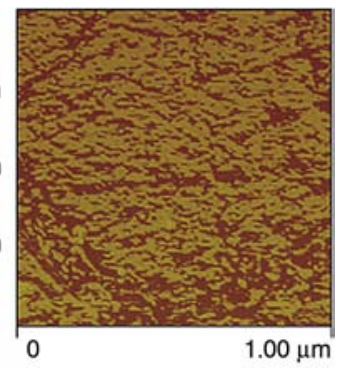

Figure 4. Height (left) and phase contrast (right) AFM images taken from the polished surface of $\mathrm{VE} / \mathrm{AESO}=50 / 50 \mathrm{wt} \%$ hybrid

A deeper insight in the morphology was expected from AFM investigations. The related height and phase AFM images are shown in Figure 4. By contrast to VE, which exhibits a clear nodular structure (nodules is in the range of 50-70 nm [18]), the structure of $\mathrm{VE} / \mathrm{AESO}=50 / 50 \mathrm{wt} \%$ hybrid is likely an IPN. This is substantiated by the AFM phase image in Figure 4, in which the AESO-rich phase is dark (being 'soft'), whereas the VE-rich one is white (being 'hard'). Note that both phases are likely intermingled, continuous. In order to deliver direct evidence for the formation of IPN, transmission electron microscopic (TEM) inspection should be carried out on suitably stained samples. Nonetheless, the IPN structuring with nanoscaleentities (cf. Figure 4) should be favored by the styrene acting as reactive comonomer for the crosslinking of both VE and AESO.

\subsection{Flexural mechanical properties}

The static flexural properties (modulus $\left(E_{\mathrm{f}}\right)$, strength $\left(\sigma_{\mathrm{f}}\right)$ and strain $\left(\varepsilon_{\mathrm{f}}\right)$ - the two latter taken at the maximum load) of the systems studied are listed in Table 2. As expected according to the DMTA

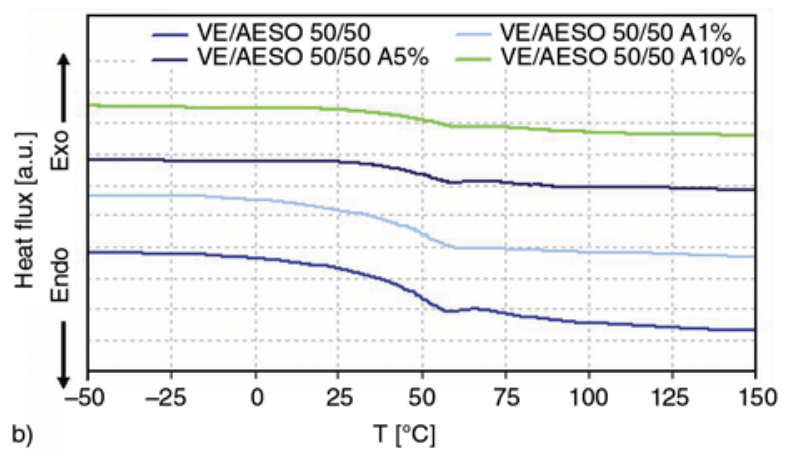

Figure 3. a) DSC traces showing the $T_{\mathrm{g}}$ steps for VE and VE/AESO hybrids of different compositions, b) DSC traces showing the $T_{\mathrm{g}}$ steps for $\mathrm{VE} / \mathrm{AESO}=50 / 50 \mathrm{wt} \%$ hybrid with and without phthalic anhydride (A) in different amounts 
Table 2. Flexural (modulus, $E_{\mathrm{f}}$, strength, $\sigma_{\mathrm{f}}$, and strain, $\varepsilon_{\mathrm{f}}$, at maximal load) and fracture mechanical $\left(K_{\mathrm{c}}\right.$ and $\left.G_{\mathrm{c}}\right)$ properties of VE and $\mathrm{VE} / \mathrm{AESO}$ hybrids

\begin{tabular}{|c|c|c|c|c|c|}
\hline \multirow{3}{*}{ Material } & \multicolumn{5}{|c|}{ Properties } \\
\hline & \multicolumn{3}{|c|}{ Flexure } & \multicolumn{2}{|c|}{ Fracture mechanics } \\
\hline & $\mathbf{E}_{\mathrm{f}}[\mathbf{M P a}]$ & $\sigma_{\mathrm{f}}[\mathrm{MPa}]$ & $\varepsilon_{\mathrm{f}}[\%]$ & $\mathrm{K}_{\mathrm{c}}\left[\mathrm{MPa} \cdot \mathrm{m}^{1 / 2}\right]$ & $\mathbf{G}_{\mathrm{c}}\left[\mathrm{kJ} \cdot \mathbf{m}^{2}\right]$ \\
\hline VE & $3212 \pm 137$ & $123 \pm 24$ & $4.3 \pm 0.8$ & $0.55 \pm 0.05$ & $0.20 \pm 0.01$ \\
\hline VE/AESO 75/25 & $2778 \pm 140$ & $112 \pm 8$ & $5.1 \pm 1.0$ & $0.59 \pm 0.04$ & $0.22 \pm 0.02$ \\
\hline VE/AESO 50/50 & $1516 \pm 120$ & $61 \pm 3$ & $5.9 \pm 0.7$ & $0.70 \pm 0.03$ & $0.37 \pm 0.04$ \\
\hline VE/AESO 50/50 A1\% & $1654 \pm 148$ & $65 \pm 3$ & $5.8 \pm 0.4$ & $0.63 \pm 0.05$ & $0.33 \pm 0.05$ \\
\hline VE/AESO 50/50 A $5 \%$ & $1683 \pm 119$ & $66 \pm 8$ & $5.6 \pm 0.3$ & $0.73 \pm 0.06$ & $0.39 \pm 0.05$ \\
\hline VE/AESO 50/50 A10\% & $1803 \pm 144$ & $72 \pm 8$ & $5.5 \pm 0.3$ & $0.55 \pm 0.03$ & $0.28 \pm 0.04$ \\
\hline VE/AESO 25/75 & $234 \pm 33$ & $15 \pm 2$ & $16.3 \pm 1.5$ & $0.36 \pm 0.01^{*}$ & $0.68 \pm 0.03^{*}$ \\
\hline
\end{tabular}

*Designation: computed by considering the load maximum as the prerequisites of the linear elastic fracture mechanics did not hold anymore

results, $E_{\mathrm{f}}$ decreased with increasing AESO content. A similar tendency was detected for the flexural strength. On the other hand, the flexural strain slightly increased with increasing AESO content until its content reached $50 \mathrm{wt} \%$. By contrast, the $\mathrm{VE} / \mathrm{AESO}=25 / 75 \mathrm{wt} \%$ hybrid exhibited very high

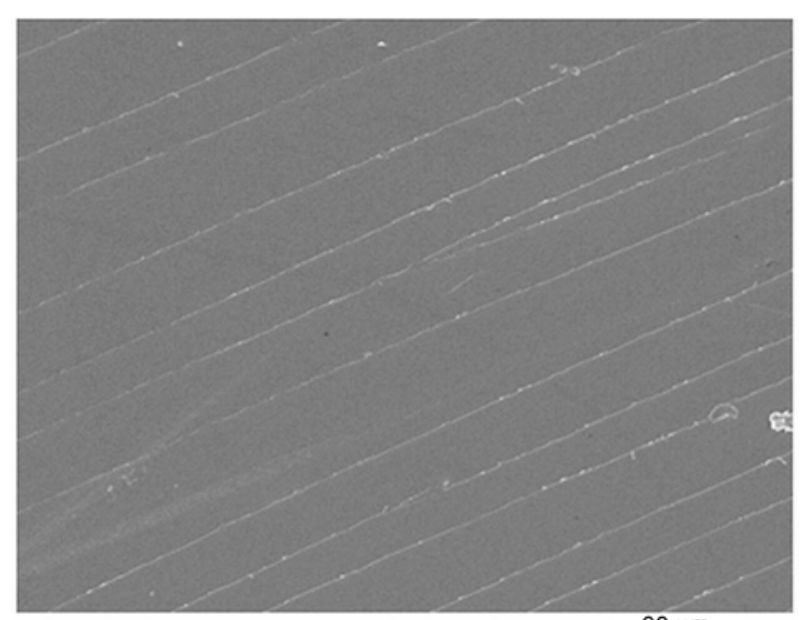

a)

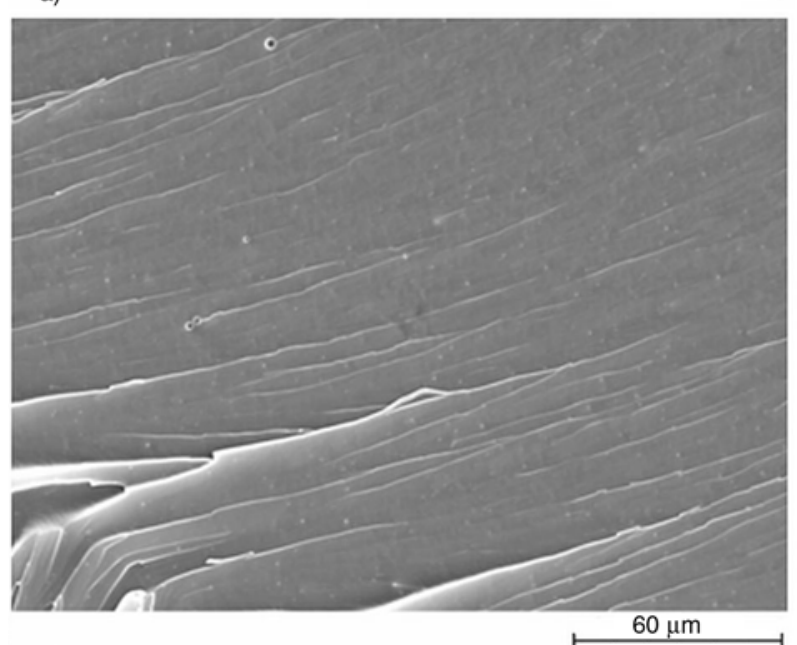

c) ductility, reflected by the related high $\varepsilon_{\mathrm{f}}$ value (cf. Table 1). Incorporation of $\mathrm{A}$ in more and more amount yielded the opposite tendency. This suggests that the proposed grafting between VE and AESO took place, in fact.

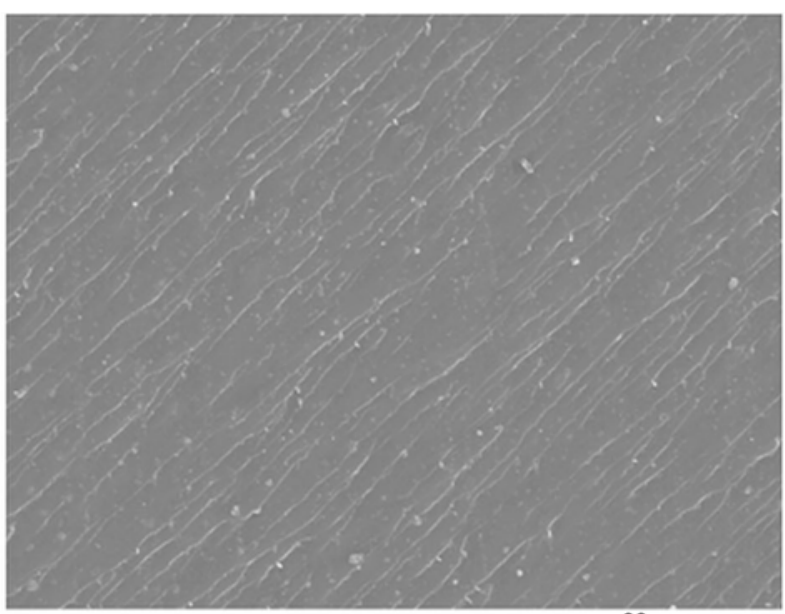

b)

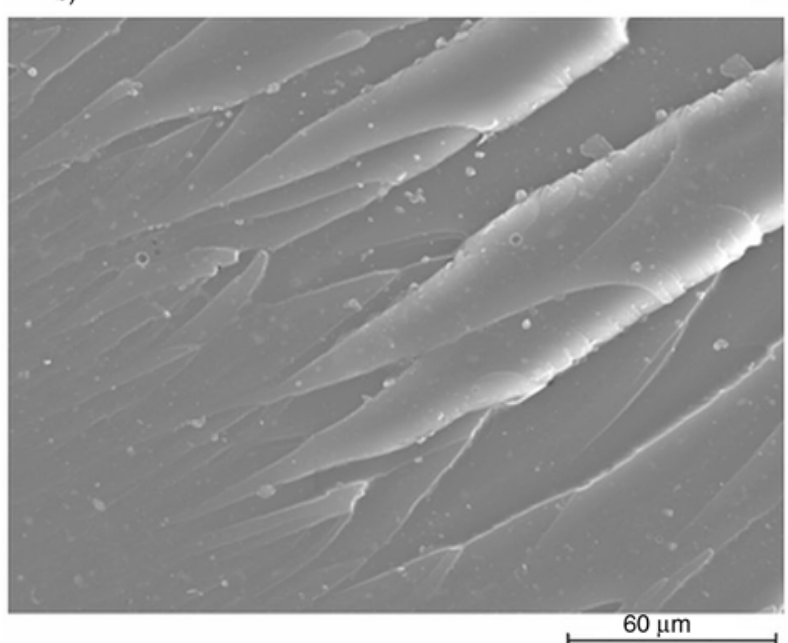

d)

Figure 5. SEM pictures taken from the fracture surfaces of VE (a), VE/AESO $=75 / 25 \mathrm{wt} \%$ (b), VE $/ \mathrm{AESO}=50 / 50 \mathrm{wt} \%$ (c), and $\mathrm{VE} / \mathrm{AESO}=25 / 75 \mathrm{wt} \%$ (d) 


\subsection{Fracture mechanical properties and failure mode}

The fracture toughness and energy data $\left(K_{\mathrm{c}}\right.$ and $G_{\mathrm{c}}$, respectively) for the systems studied are also summarized in Table 2. Note that both the $K_{\mathrm{c}}$ and $G_{\mathrm{c}}$ parameters increased with increasing AESO content. This tendency is seldom because increasing $K_{\mathrm{c}}$ is usually accompanied with decreasing $G_{\mathrm{c}}$ if the modulus (and Poisson ratio) of the related systems does not change much. However, the modulus of the hybrids changed markedly (cf. Table 2) which is the major reason for the enhanced $G_{\mathrm{c}}$. The simplest explanation for increasing $K_{\mathrm{c}}$ is that with increasing AESO content the related hybrids, due to their peculiar phase structure, become less notch-sensitive.

Figure 5 displays characteristic SEM pictures taken from the fracture surface of VE and VE/AESO hybrids. One can see that the fracture surface becomes rougher with increasing AESO content of

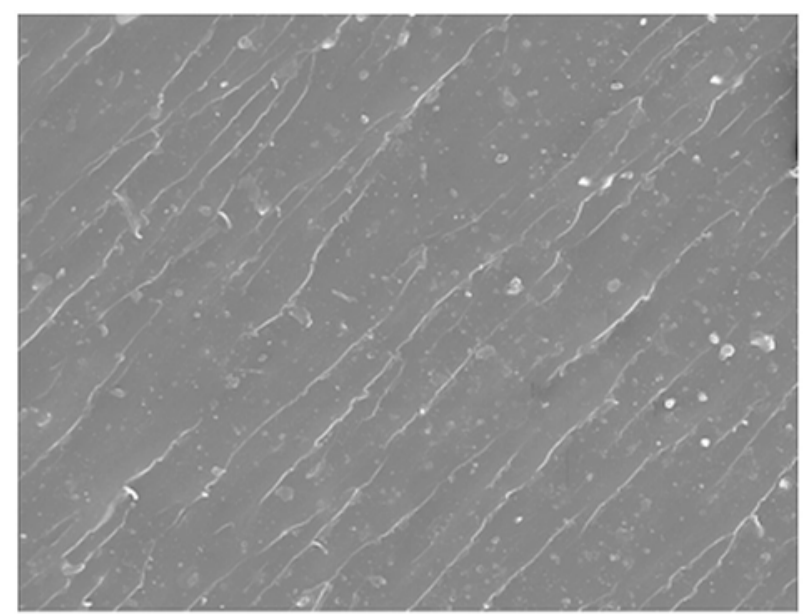

a)

$30 \mu \mathrm{m}$

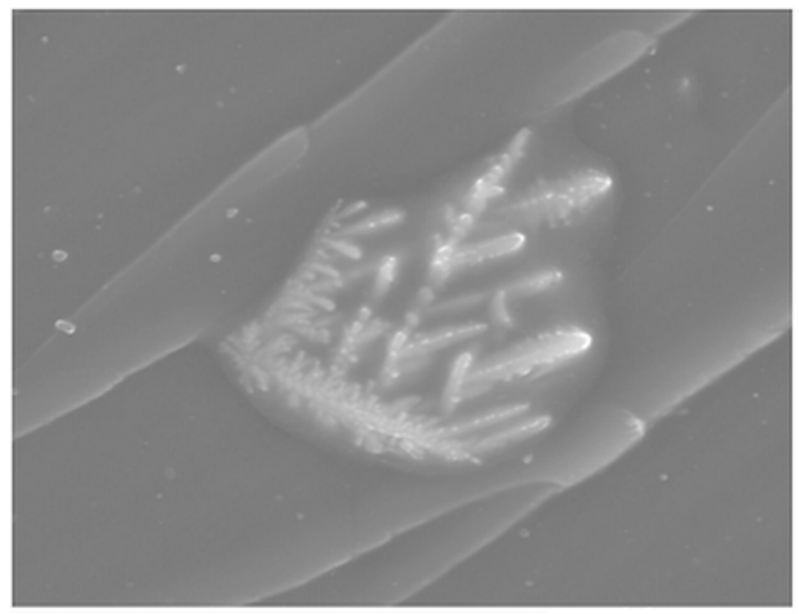

c)

$30 \mu \mathrm{m}$ the hybrids. This is a clear indication for the enhancement of the fracture energy. The shearsteps, termed 'river like' pattern, in the fracture surfaces of the hybrids suggest that they failed by shear deformation. It is noteworthy that the shear deformation is strongly supported by the IPN structure as argued by Karger-Kocsis [16].

Inspection of the fracture surfaces of the hybrids yielded some further insight in their morphology. Especially in case of the hybrids VE/AESO $=75 / 25$ and $25 / 75 \mathrm{wt} \%$ dendritic inclusions could be found - cf. Figure 6 . The reason for the appearance of such inclusions is unknown by the authors. Similar dendritic formations were reported for VE-based systems toughened by polymerizable hyperbranched and star-shaped polymers [19], and for IPNs composed of polymethyl methacrylate and polyurethane that contained unsaturated plant oils [20]. In the former case the authors [19] claimed that the dendritic inclusions were formed mostly by

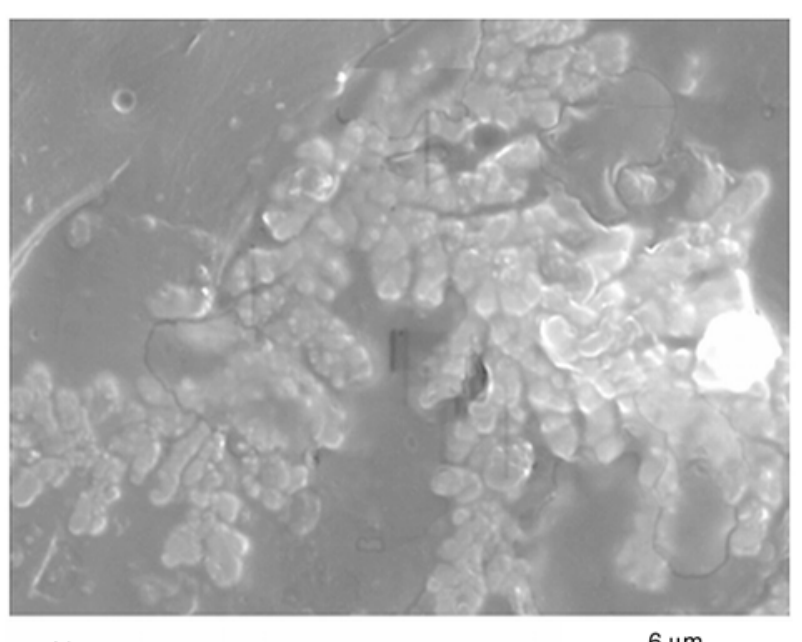

b)

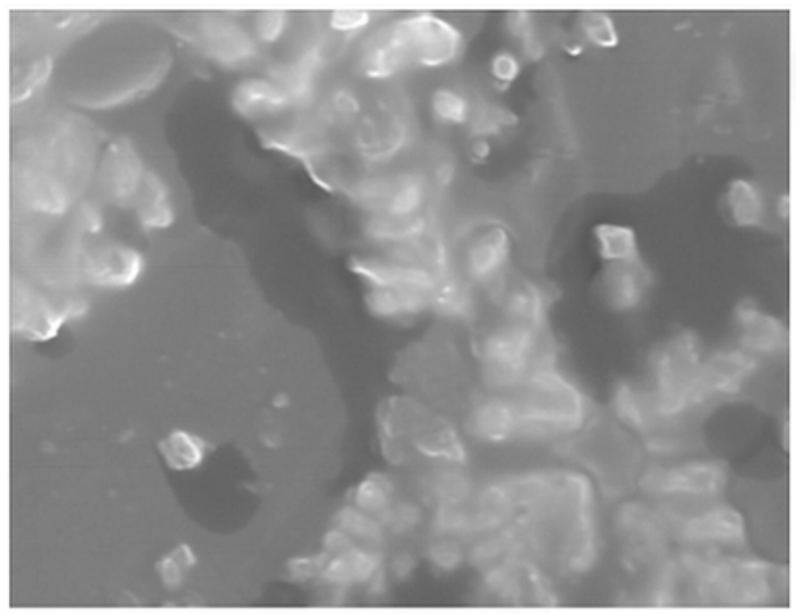

d)
$6 \mu \mathrm{m}$

Figure 6. SEM pictures taken from the fracture surfaces of VE/AESO $=75 / 25 \mathrm{wt} \%(\mathrm{a}, \mathrm{b})$, and $\mathrm{VE} / \mathrm{AESO}=25 / 75 \mathrm{wt} \%(\mathrm{c}, \mathrm{d})$ 
homopolymerization of the toughening additive. We think that in the VE/AESO hybrids the onset of these dendritic inclusions is due to AESO homoand $\mathrm{AESO} /$ styrene copolymerization reactions.

This is the right place to give some further notes on the IPN-structure proposed. As it was mentioned in manuscript, the coexistence of two continuous phases was detected on nano-level by AFM. Additionally, the two-phase structure of VE/AESO systems was confirmed by DMTA ( $\alpha$ - and $\alpha^{\prime}$-relaxations, respectively). Finally, hyperbranched structures were detected by SEM in the case of hybrids with 'unbalanced' compositions (i.e. VE/AESO $25 / 75$ and $75 / 25 \mathrm{wt} \%$ ). In our opinion, the difference in the reactivity of components, bearing different functional groups and functionality (this was discussed for AESO and styrene in Ref. [21], recently), is the main reason for the formation of the hybrid networks having IPN-like structure.

Moreover, the influence of steric hindrances on the (co)polymerization of the components (AESOstyrene, VE-styrene, AESO-VE) caused by the long alkyl chains of AESO is markedly stronger in com-

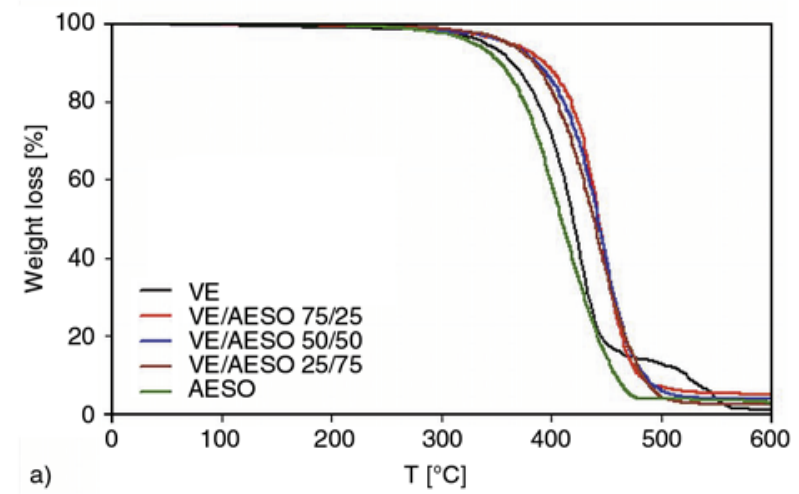

parison to the aromatic structured VE. This results in the simultaneous formation of separate VEstyrene and AESO-styrene networks having relatively low inter-grafting degree. Note that gelation of the systems already occurred at ambient temperature. The high functionality and unsaturation level of AESO triggered the formation of hyperbranched structures on micron-scale. This indicates the high homopolymerization ability of AESO, yielding a multiphase structure. The latter was confirmed by DMTA and DSC results. By contrast, VE molecules having only two acrylic and two secondary hydroxyl groups are not able to form such dendritic structures. The fact that hyperbranched structures were only detected in the VE/AESO 25/75 and 75/25 wt $\%$ systems can be ascribed to the effect of the major component of the composition. The major component will be crosslinked, whereas the minor one pre-gelated, and its further crosslinking occurs in presence of the crosslinked network of the major component. In case of the 'balanced' composition (VE/AESO 50/50 wt\%) the gelation and crosslinking of both components (no concentration influ-

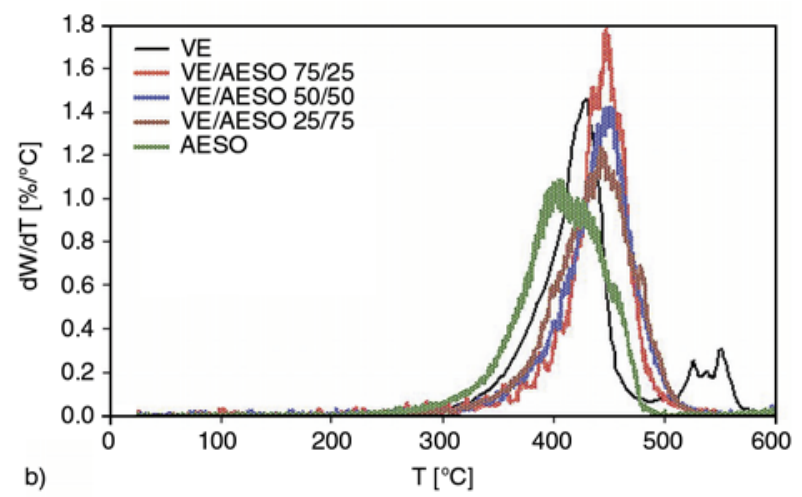

Figure 7. a) TGA traces for VE and VE/AESO hybrids of different compositions, b) Derivative TGA traces for VE and VE/AESO hybrids of different compositions
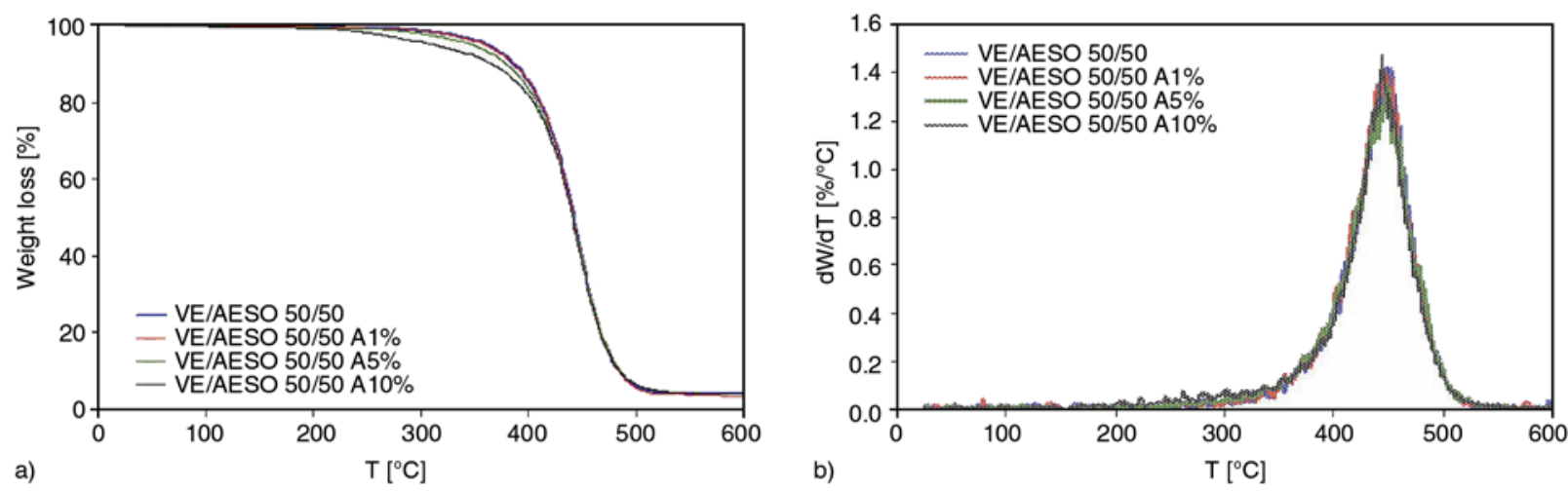

Figure 8. a) TGA traces for VE/AESO $=50 / 50 \mathrm{wt} \%$ hybrid with and without phthalic anhydride (A) in different amounts, b) Derivative TGA traces for VE/AESO $=50 / 50 \mathrm{wt} \%$ hybrid with and without phthalic anhydride (A) in different amounts 
ence) occurred parallel excluding the appearance of dendritic structures.

\subsection{Thermogravimetric analysis (TGA)}

The TGA yielded some unexpected results. The TGA curves in Figure 7 show that the resistance to thermal degradation of the hybrids is higher than that of either VE or AESO. The most straightforward explanation for such synergistic effect is that the confined molecular structure within the IPN hampers the decomposition and the subsequent diffusion/volatilization of the decomposition products. If this explanation holds, then incorporation of phthalic anhydride should give even better results as the onset of grafted IPN is accompanied with even higher molecular 'confinement'. This was, however, not the case as one can observe in Figure 8. Increasing amount of $\mathrm{A}$ did not result in a further shift in the TGA traces towards higher temperature. The observed effect may also be linked with the A itself because it might have been in surplus (i.e. without coupling the phases) in the recipe or working as initiation site during thermal decomposition.

\section{Conclusions}

Based on this work devoted to study the structure, (fracture) mechanical and thermal behaviors of hybrid resins, composed of styrene crosslinkable vinyl ester (VE) and acrylated epoxidized soybean oil (AESO), crosslinked in the presence and absence of phthalic anhydride as phase coupling agent and additional crosslinker, the following conclusions can be drawn:

- The structure of the hybrids VE/AESO = $75 / 25 \ldots 25 / 75 \mathrm{wt} \%$ is likely IPN type. This was deduced from results achieved by different techniques giving direct (AFM) and indirect hints (DMTA, SEM, TGA), respectively. Nevertheless, the presence of IPN structure should be confirmed, possibly by TEM.

- With increasing AESO amount, beside of $T_{\mathrm{g}}$, also the flexural modulus and strength of the hybrids were reduced, whereas their ductility (flexural strain) enhanced. Additional use of phthalic anhydride in the recipe yielded mostly an adverse trend in the above-mentioned properties. Both $K_{\mathrm{c}}$ and $G_{\mathrm{c}}$ were improved by increasing AESO hybridization. Incorporation of phthalic anhydride did not cause a pronounced change in the above fracture mechanical parameters.

- The hybrids showed improved resistance to thermal decomposition compared to the parent VE and AESO. This was attributed to the presence of IPN structure owing to the related confined molecular structure hindering the decomposition and follow-up processes.

We can sum up that hybridization of AESO with VE is a promising strategy to develop hybrid resins with tailored thermal and mechanical properties, which are suited for engineering applications.

\section{Acknowledgements}

This work was performed in the framework of a bilateral cooperation program between Germany (DAAD) and Hungary (MöB). It is also connected to the scientific program of the 'Development of quality-oriented and harmonized $\mathrm{R}+\mathrm{D}+\mathrm{I}$ strategy and functional model at BME', supported by the New Hungary Development Plan (Project ID: TÁMOP-4.2.1/B-09/1/KMR-2010-0002).

\section{References}

[1] Khot S. N., Lascala J. J., Can E., Morye S. S., Williams G. I., Palmese G. R., Kusefoglu S. H., Wool R. P.: Development and application of triglyceridebased polymers and composites. Journal of Applied Polymer Science, 82, 703-723 (2001).

DOI: 10.1002/app.1897

[2] Raquez J-M., Deléglise M., Lacrampe M-F., Krawczak P.: Thermosetting (bio)materials derived from renewable resources: A critical review. Progress in Polymer Science, 35, 487-509 (2010).

DOI: $10.1016 /$ j.progpolymsci.2010.01.001

[3] Zhu J., Chanrashekhara K., Flanigan V., Kapila S.: Curing and mechanical characterization of a soy-based epoxy resin system. Journal of Applied Polymer Science, 91, 3513-3518 (2004).

DOI: $10.1002 /$ app. 13571

[4] Miyagawa H., Jurek R. J., Mohanty A. K., Misra M., Drzal L. T.: Biobased epoxy/clay nanocomposites as a new matrix for CFRP. Composites Part A: Applied Science and Manufacturing, 37, 54-62 (2006). DOI: $10.1016 /$ j.compositesa.2005.05.014

[5] Miyagawa H., Misra M., Drzal L. T., Mohanty A. K.: Fracture toughness and impact strength of anhydridecured biobased epoxy. Polymer Engineering and Science, 45, 487-495 (2005).

DOI: $10.1002 /$ pen. 20290 
[6] Boyd S. E., La Scala J. J., Palmese G. R.: Molecular relaxation behavior of fatty acid-based vinyl ester resin. Journal of Applied Polymer Science, 108, 34953506 (2008).

DOI: $10.1002 /$ app. 27957

[7] Haq M., Burgueño R., Mohanty A. K., Misra M.: Biobased unsaturated polyester/layered silicate nanocomposites: Characterization and thermo-physical properties. Composites Part A: Applied Science and Manufacturing, 40, 540-547 (2009).

DOI: 10.1016/j.compositesa.2009.02.008

[8] Raghavachar R., Letasi R. J., Kola P. V., Chen Z., Massingill J. L.: Rubber-toughening epoxy thermosets with epoxidized crambe oil. Journal of the American Oil Chemists' Society, 76, 511-516 (1999).

DOI: 10.1007/s11746-999-0033-3

[9] Lu J., Wool R. P.: Additive toughening effects on new bio-based thermosetting resins from plant oils. Composites Science and Technology, 68, 1025-1033 (2008). DOI: 10.1016/j.compscitech.2007.07.009

[10] Meier M. A. R., Metzger J. O., Schubert U. S.: Plant oil renewable resources as green alternatives in polymer science. Chemical Society Reviews, 36, 17881802 (2007).

DOI: $10.1039 / \mathrm{b} 703294 \mathrm{c}$

[11] Lu J., Khot S., Wool R. P.: New sheet molding compound resins from soybean oil. I. Synthesis and characterization. Polymer, 46, 71-80 (2005).

DOI: $10.1016 /$ j.polymer.2004.10.060

[12] Lu J., Wool R. P.: Novel thermosetting resins for SMC applications from linseed oil: Synthesis, characterization, and properties. Journal of Applied Polymer Science, 99, 2481-2488 (2006).

DOI: $10.1002 /$ app. 22843

[13] Barrett L. W., Sperling R. H., Murphy C. J.: Naturally functionalized triglyceride oils in interpenetrating polymer networks. Journal of the American Oil Chemists' Society, 70, 523-534 (1993).

DOI: $10.1007 / \mathrm{BF} 02542588$
[14] La Scala J., Wool R. P.: Property analysis of triglyceride-based thermosets. Polymer, 46, 61-69 (2005). DOI: $10.1016 /$ j.polymer.2004.11.002

[15] Fu L., Yang L., Dai C., Zhao C., Ma L.: Thermal and mechanical properties of acrylated expoxidized-soybean oil-based thermosets. Journal of Applied Polymer Science, 117, 2220-2225 (2010).

DOI: $10.1002 /$ app.32126

[16] Karger-Kocsis J.: Simultaneous interpenetrating network structured vinylester/epoxy hybrids and their use in composites. in 'Micro- and nanostructured multiphase polymer blend systems: Phase morphology and interfaces' (eds.: Harrats C., Thomas S., Groeninckx G.) CRC Press, Boca Raton, 273-293 (2006).

[17] Dos Santos Martini D., Aguiar Braga B., Samios D.: On the curing of linseed oil epoxidized methyl esters with different cyclic dicarboxylic anhydrides. Polymer, 50, 2919-2925 (2009).

DOI: $10.1016 /$ j.polymer.2009.03.058

[18] Karger-Kocsis J., Gryshchuk O., Schmitt S.: Vinylester/ epoxy-based thermosets of interpenetrating network structure: An atomic force microscopic study. Journal of Materials Sciences, 38, 413-420 (2003).

DOI: $10.1023 / \mathrm{A}: 1021855228253$

[19] Karger-Kocsis J., Fröhlich J., Gryshchuk O., Kautz H., Frey H., Mülhaupt R.: Synthesis of reactive hyperbranched and star-like polyethers and their use for toughening of vinylester-urethane hybrid resins. Polymer, 45, 1185-1195 (2004).

DOI: $10.1016 /$ j.polymer.2003.12.050

[20] Kong X., Narine S. S.: Sequential interpenetrating polymer networks produced from vegetable oil based polyurethane and poly(methyl methacrylate). Biomacromolecules, 9, 2221-2229 (2008).

DOI: $10.1021 / \mathrm{bm} 800335 \mathrm{x}$

[21] Şen S., Çayli G.: Synthesis of bio-based polymeric nanocomposites from acrylated epoxidized soybean oil and montmorillonite clay in the presence of a biobased intercalant. Polymer International, 59, 11221129 (2010).

DOI: $10.1002 /$ pi.2838 